\title{
FEMALE AND MALE CARRIERS OF TAZ MUTATIONS NEED TO BE THOROUGHLY INVESTIGATED
}

\author{
Finsterer J*, Stollberger C
}

*Corresponding Author: Josef Finsterer, M.D., Ph.D., Krankenanstalt Rudolfstiftung, Postfach 20, 1180 Vienna, Austria. Tel: +43-1-71165. Fax. +43-1-4781711. E-mail: fifigs1@yahoo.de

\section{Dear Editor,}

We read with interest the article by Bakšienè et al. about a 22-year-old female carrier of a novel $T A Z$ variant causing Barth syndrome and her two manifesting brothers [1]. We have the following comments and concerns.

In up to $50.0 \%$ of cases, Barth syndrome is associated with left ventricular hypertrabeculation (LVHT), also known as noncompaction [2]. Were the two manifesting brothers of the index case investigated for LVHT? This is of particular interest as one of her brothers had developed fibroelastosis [1] and because subendocardial fibroelastosis is frequently associated with LVHT [3]. Did the two manifesting brothers undergo follow-up investigations as LVHT may occasionally develop after birth in Barth syndrome [4]. Was the family history positive for complications of LVHT, such as heart failure, ischemic cerebral stroke, arrhythmias, or sudden cardiac death? Left ventricular hypertrabeculation can be diagnosed during intrauterine development by ultrasound [5].

Both brothers of the index case are reported to have developed myocarditis [1]. The golden standard for diagnosing myocarditis is endomyocardial biopsy. Was the diagnosis "myocarditis" established upon endomyocardial biopsy in both of them? Was the diagnosis established upon cardiac magnetic resonance imaging (MRI) with contrast medium or was it only a clinical suspicion? Was myocarditis assumed to be due to a viral or bacterial infection or due to an immunological response? Which therapy was applied for myocarditis?

Since Barth syndrome is X-linked, transmitted by female carriers, and since some female carriers might manifest clinically [6], depending on the amount of inactivated $\mathrm{X}$-chromosomes carrying the mutated gene, it would be interesting to know if the index case presented with any phenotypic features of Barth syndrome. Female carriers may manifest with dilated cardiomyopathy, hypertrophic cardiomyopathy, LVHT, heart failure, myopathy leading to muscle weakness, and neutropenia associated with recurrent infections and sepsis [6]. Because the mutation was also found in the mother and grandmother from the mother's side of the index case, we should be informed if they had developed clinical manifestations of the disease as well.

Patients carrying $T A Z$ mutations may not only manifest with the canonical features of Barth syndrome but also with a number of other phenotypic manifestations $[7,8]$. These include dysmorphism (full cheeks, deep set eyes, prominent ears), ventricular arrhythmias, sudden cardiac death, ischemic stroke, methyl-glutaconic asciduria, impaired visuo-spatial skills, mild cognitive impairment (learning disability, attention deficit), delayed motor milestones, delayed onset of puberty, feeding abnormalities, preference for salty and spicy food, strong gag reflex, lactic acidosis, miscarriages/stillbirths, recurrent infectious oral ulcers, perianal dermatitis, hyperlpidemia, osteopenia, delayed bone age, scoliosis and growth delay $[7,8]$. Were any of these additional manifestions found in the clinically manifesting carriers of the $T A Z$ mutation in the described family?

Overall, this interesting case series would be more meaningful if more clinical data would have been provided and if carriers of the mutation would have been systematically investigated for LVHT. Furthermore, female carriers of $T A Z$ mutations need to be investigated for subclinical or mild manifestations of the disease.

Declaration of Interest. The authors report no conflicts of interest. The authors alone are responsible for the content and writing of this article. 


\section{REFERENCES}

1. Bakšienė $M$, Benušienė $E$, Morkūnienė A, Ambrozaitytė L, Utkus A, Kučinskas V. A novel intronic splice site tafazzin gene mutation detected prenatally in a family with Barth syndrome. BJMG. 2017; 19(2): 95-100.

2. Spencer CT, Bryant RM, Day J, Gonzalez IL, Colan $\mathrm{SD}$, Thompson WR, et al. Cardiac and clinical phenotype in Barth syndrome. Pediatrics. 2006; 118(2): e337-46.

3. Burke A, Mont E, Kutys R, Virmani R. Left ventricular noncompaction: a pathological study of 14 cases. Hum Pathol. 2005; 36(4): 403-411.

4. Woiewodski L, Ezon D, Cooper J, Feingold B. Barth Syndrome with late-onset cardiomyopathy: A missed opportunity for diagnosis. J Pediatr. 2017; 183: 196-198.
5. Stollberger C, Wegner C, Finsterer J. Fetal ventricular hypertrabeculation/noncompaction: Clinical presentation, genetics, associated cardiac and extracardiac abnormalities and outcome. Pediatr Cardiol. 2015; 36(7): 1319-1326.

6. Cosson L, Toutain A, Simard G, Kulik W, Matyas G, Guichet A, et al. Barth syndrome in a female patient. Mol Genet Metab. 2012; 106(1): 115-120.

7. Ferreira C, Thompson R, Vernon H. Barth Syndrome. In: Pagon RA, Adam MP, Ardinger HH, Wallace SE, Amemiya A, Bean LJH, et al., Eds. GeneReviews ${ }^{\circledR}$ [Internet]. Seattle, WA, USA: University of Washington, Seattle. 1993-2017 (Available from http://www. ncbi.nlm. nih.gov/books/NBK247162/).

8. Jefferies JL. Barth syndrome. Am J Med Genet C Semin Med Genet. 2013; 163C: 198-205.

RESPONSE TO THE LETTER TO THE EDITOR

\title{
A NOVEL INTRONIC SPLICE SITE TAFAZZIN GENE MUTATION DETECTED PRENATALLY IN A FAMILY WITH BARTH SYNDROME
}

\author{
Bakšienė M*, Benušienė E, Morkūnienė A, Ambrozaitytė L, Utkus A, Kučinskas V
}

*Corresponding Author: Marija Bakšienė, M.D., Centre for Medical Genetics, Vilnius University Hospital Santaros Klinikos, Santariškių 2, LT-08406 Vilnius, Lithuania. E-mail: m.baksiene@gmail.com

\section{Dear Editor,}

This is a response to Drs. Josef Finsterer and Claudia Stцllberger' Letter to the Editor expressing his observations and concerns about the article "A Novel Intronic Splice Site Taffazin Gene Mutation Detected Prenatally in a Family with Barth Syndrome."

We would like to remind the readers that the affected family consisted of four children: the first boy was healthy, the second brother died at 6 months of age due to cardiac failure, the third brother was diagnosed with Barth syndrome and died at 11 years of age; the youngest sister is the carrier of the mutation. To investigate the case further, we managed to retrieve archived medical records of the deceased third brother. Provided below is the additional medical evidence we collected.
The first comment queried whether the two manifesting brothers of the index case had been investigated for LVHT (left ventricular hypertrabeculation, also known as noncompaction). Prenatal ultrasound did not show any cardiac pathology for both brothers. However, that may have been due to the poor quality of ultrasound machines available at local medical care centers and insufficient experience of the ultrasound operators at the time (1991 and 1998).

Cardiovascular ultrasound was performed after birth and both affected boys were diagnosed with endocardial fibroelastosis within the first month of their lives. Due to very good clinical response to treatment, the diagnosis was changed to congenital myocarditis for both of them. The therapy applied for myocarditis for the second brother of the affected family is not known. He died at 6 months of 
age. The autopsy reported undifferentiated cardiomyopathy. As for the third brother of the family, he was treated with digoxin, enalapril, diuretics and prednisolone. Both children had regular cardiovascular ultrasound tests and there was no suspicion of LVHT. The family history was negative for complications of LVHT, such as heart failure, ischemic cerebral stroke, arrhythmias, or sudden cardiac death. Endomyocardial biopsy and cardiac magnetic resonance imaging (MRI) with contrast medium were not performed on either of the affected brothers according to the medical archives.

Another concern was regarding female carriers and whether they had developed clinical manifestations of the disease. As it was reported in the article, the proband and her mother had normal electrocardiograms and echocardiograms and no history of cardiac disease. The maternal grandmother of the proband, currently 85 years of age, has primary hypertension, coronary heart disease, chronic atrial fibrillation, type II diabetes and hypertensive and diabetic nephropathy.
Lastly, Dr. Josef Finsterer's letter inquired whether any additional manifestions of Barth syndrome had been found in the clinically manifesting carriers of the $T A Z$ mutation in the described family. In addition to dilated cardiomyopathy, hypoglycaemia, cardiac insufficiency, repeated episodes of neutropenia, growth retardation and hypotonia, excess amounts of 3-methylglutaric and 3-methylglutaconic acids in urine and low free carnitine in blood, the third boy of the family was diagnosed with recurrent infectious oral ulcers, combined specific developmental disorder, refractory generalized epilepsy, sleeping disorder, metabolic encephalopathy, spastic quadriparesis, which progressed to quadriplegia.

We hope the additional medical observations described in this response will prove meaningful to the interested medical community.

Declaration of Interest. The authors report no conflicts of interest. The authors alone are responsible for the content and writing of this article. 